\title{
Goofy Coordinates the Acuity of Olfactory Signaling
}

\author{
Tomomi Kaneko-Goto, ${ }^{1 *}$ Yuki Sato, ${ }^{1 \star}$ Sayako Katada, ${ }^{1,2 *}$ Emi Kinameri, ${ }^{1}$ Sei-ichi Yoshihara, ${ }^{1}$ Atsushi Nishiyori, ${ }^{1}$ \\ Mitsuhiro Kimura, ${ }^{1}$ Hiroko Fujita, ${ }^{1}$ Kazushige Touhara, ${ }^{2,3}$ Randall R. Reed, ${ }^{4}$ and Yoshihiro Yoshihara ${ }^{1,3}$ \\ ${ }^{1}$ RIKEN Brain Science Institute, Saitama 351-0198, Japan, ${ }^{2}$ Department of Applied Biological Chemistry, The University of Tokyo, Tokyo 113-8657, Japan, \\ ${ }^{3}$ ERATO Touhara Chemosensory Signal Project, JST, The University of Tokyo, Tokyo 113-8657, Japan, and ${ }^{4}$ Center for Sensory Biology, Johns Hopkins \\ School of Medicine, Baltimore, Maryland 21205
}

The basic scheme of odor perception and signaling from olfactory cilia to the brain is well understood. However, factors that affect olfactory acuity of an animal, the threshold sensitivity to odorants, are less well studied. Using signal sequence trap screening of a mouse olfactory epithelium cDNA library, we identified a novel molecule, Goofy, that is essential for olfactory acuity in mice. Goofy encodes an integral membrane protein with specific expression in the olfactory and vomeronasal sensory neurons and predominant localization to the Golgi compartment. Goofy-deficient mice display aberrant olfactory phenotypes, including the impaired trafficking of adenylyl cyclase III, stunted olfactory cilia, and a higher threshold for physiological and behavioral responses to odorants. In addition, the expression of dominant-negative form of cAMP-dependent protein kinase results in shortening of olfactory cilia, implying a possible mechanistic link between cAMP and ciliogenesis in the olfactory sensory neurons. These results demonstrate that Goofy plays an important role in establishing the acuity of olfactory sensory signaling.

\section{Introduction}

The olfactory system integrates sophisticated molecular, cellular, and neural circuit mechanisms for detection and discrimination of a huge variety of odorants in the environment (Axel, 1995; Mori et al., 1999; Mori and Sakano, 2011). Odor molecules inhaled into an animal's nostrils are detected by the olfactory sensory neurons (OSNs) in the olfactory epithelium (OE) (Buck, 2000). OSNs are bipolar, extending a single axon basally toward the olfactory bulb (OB) and a single dendrite apically toward the epithelial surface. Several long cilia emanate from the dendritic knob into the nasal mucus for efficient reception of odorants (McEwen et al., 2008).

Upon odorant binding to the olfactory cilia, action potentials are generated by the OSN's signal transduction machinery (Reed, 1992; Touhara and Vosshall, 2009). This signaling process occurs

Received Oct. 23, 2012; revised May 29, 2013; accepted June 26, 2013.

Author contributions: Y.S. and Y.Y. designed research; T.K.-G., Y.S., S.K., E.K., S.Y., A.N., M.K., H.F., and Y.Y. performed research; K.T. and R.R.R. contributed unpublished reagents/analytic tools; T.K.-G., Y.S., S.K., E.K., S.Y., and A.N. analyzed data; Y.Y. wrote the paper.

This work was supported by a grant from RIKEN Brain Science Institute to Y.Y.; a grant from Exploratory Research for Advanced Technology (ERATO) Touhara Chemosensory Signal Project of the Japan Sciences and Technology Agency (JST) to K.T. and Y.Y.; a Grant-in-Aid for Scientific Research (B); (KAKENHI 16300105) to Y.Y.; a Scientific Research on Priority Areas Grant (Cellular Sensor: KAKENHI 21026032 and 18077001) to Y.Y. and K.T.; a Scientific Research on Innovative Areas Grant (Systems Molecular Ethology: KAKENNHI 23115723) to Y.Y. from the Ministry of Education, Culture, Sports, Science, and Technology of Japan (MEXT); and a Research Fellowship for Young Scientists Grant from Japan Society for the Promotion of Science to S.K. We thank Charles Yokoyama and Alexandra V. Terashima for critical reading of the manuscript; Toshiaki Nakashiba for helpful advice on CDNA library construction and signal sequence trap screening; Koji Sato for help in EOG recording; Kenneth A. Jacobs for pSUC2T7M130RI vector and YTK12 yeast strain; Takeshi Imai and Hitoshi Sakano for I7(WT)-ires-ECFP and I7(WT)-ires-dnPKA-ires-EYFP transgenic mice; Frank L. Margolis for anti-OMP antibody; Sachiko Mitsui and Miwa Kawasaki for technical assistance; Brain Science Institute (BSI) Research Resource Center for help in antibody production and generation/ maintenance of transgenic and knock-out mice; and members of the Yoshihara laboratory for valuable discussions.

*T.K.-G., Y.S., and S.K. contributed equally to this work.

Correspondence should be addressed to Yoshihiro Yoshihara, PhD, Laboratory for Neurobiology of Synapse, RIKEN Brain Science Institute, 2-1 Hirosawa, Wako, Saitama 351-0198, Japan. E-mail: yoshihara@brain.riken.jp.

DOI:10.1523/JNEUROSCI.4948-12.2013

Copyright $\odot 2013$ the authors $\quad 0270-6474 / 13 / 3312987-10 \$ 15.00 / 0$ through a sequential activation of a cascade of functional molecules including odorant receptors (ORs), olfactory-specific GTPbinding protein (Golf), adenylyl cyclase III (ACIII), and cyclic nucleotide-gated cation channel, all of which are enriched in the olfactory cilia (Jones and Reed, 1989; Bakalyar and Reed, 1990; Dhallan et al., 1990; Buck and Axel, 1991). Genetic mutations in these signaling molecules lead to olfactory dysfunctions as exemplified by anosmia and hyposmia (McEwen et al., 2008).

Transmembrane and secreted proteins play important roles in a variety of developmental and functional aspects of OSNs. For example, the hierarchical and combinatorial expression of multiple guidance molecules directs convergent projection of OSN axons to target glomeruli in the OB (Mori and Sakano, 2011). In addition, there are other transmembrane and secreted proteins crucial for odor-sensing mechanisms in $\mathrm{OE}$, which facilitate the OR trafficking to plasma membranes (Saito et al., 2004), carry odor molecules in nasal mucus to ORs (Tegoni et al., 2000), and convert odorant information into intracellular second messenger elevation (Gibson and Garbers, 2000). Most of these proteins are characterized by the presence of a signal sequence with a stretch of hydrophobic amino acids at the $\mathrm{N}$ terminus.

In this study, we performed a signal sequence trap screening of mouse OE cDNA library and identified a novel transmembrane protein that is specifically expressed in OSNs and vomeronasal sensory neurons (VSNs) and predominantly localized in the Golgi apparatus. Hence, we designated this gene product as Goofy (Golgi protein in olfactory neurons). Genetic ablation of the Goofy gene caused abnormal localization of ACIII, shortening of olfactory cilia, and reduced sensitivity to odorants, indicating a crucial role of Goofy in functioning of the olfactory system.

\section{Materials and Methods}

Signal sequence trap screening. Yeast signal sequence trap screening was performed essentially as described previously (Jacobs et al., 1997; Na- 


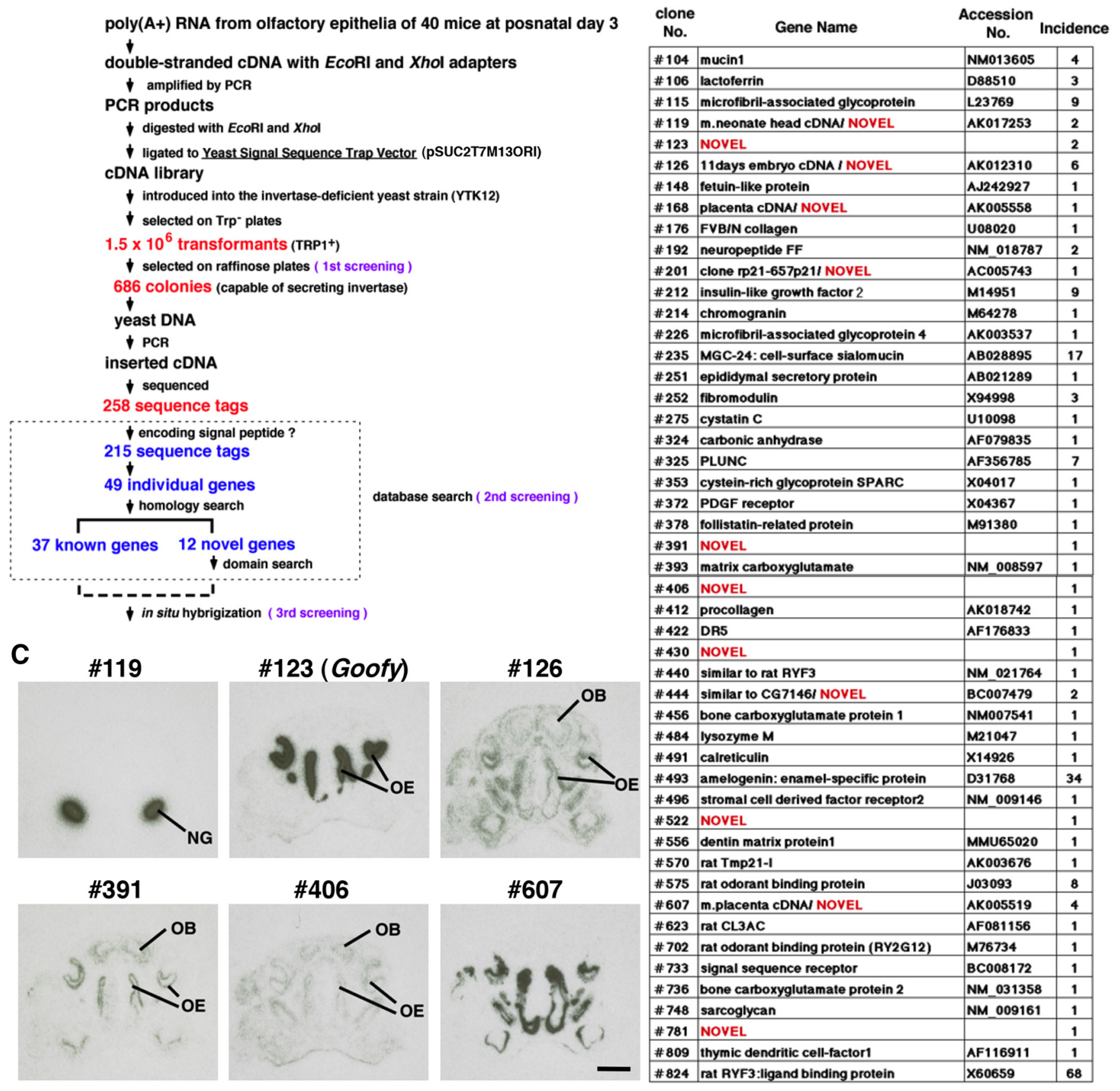

Figure 1. Discovery of Goofy (\#123) by signal sequence trap screening. $\boldsymbol{A}$, Strategy of the signal sequence trap screening for identification of novel transmembrane and secreted molecules expressed in the $\mathrm{OE}$. $\boldsymbol{B}, \mathrm{A}$ summary table for individual 49 CDNA clones obtained by the signal sequence trap screening. C, mRNA expression patterns of six novel genes in P3 $0 \mathrm{E}$ coronal sections assessed by in situ hybridization analysis. The clone \#123 (Goofy) is abundantly and specifically expressed in the OE. NG, Nasal gland. Scale bar: C, $500 \mu \mathrm{m}$.

kashiba et al., 2000). Poly(A) + RNA was prepared from postnatal day (P) 3 mouse OE, reverse-transcribed, and PCR-amplified to generate double-stranded cDNA with EcoRI and XhoI adaptors. The doublestranded cDNA was digested with EcoRI and XhoI, size-fractionated by agarose gel electrophoresis (300-800 bp), and ligated unidirectionally into pSUC2T7M13ORI vector (Jacobs et al., 1997) to construct a cDNA library. For screening of cDNAs containing signal peptide sequences, the library was introduced into the invertase-deficient yeast strain YTK12, and selected on $\operatorname{Trp}^{-}$plates followed by raffinose-containing plates on which only the transformants harboring cDNA-derived signal peptidefused invertase gene can grow. Among 686 colonies grown on raffinose plates, cDNA inserts were amplified and sequenced for 258 recombi- nants, and the presence of a putative signal peptide was confirmed for 215 clones that encoded 49 individual genes.

In situ hybridization and Northern blot analysis. In situ hybridization and Northern blot analysis were performed as described previously (Yoshihara et al., 1997). One to three mice at individual developmental stages were used for these analyses.

Antibody production. To generate anti-Goofy antibody, a peptide corresponding to the C-terminal 19 aa (RGPQRLEALSPAALSPNFF) of mouse Goofy protein was synthesized, coupled to keyhole limpet hemocyanin, and used to immunize rabbits. This antibody labeled OSNs and VSNs, and its immunoreactivity was completely absent in Goofydeficient mice, confirming its specificity to Goofy protein. Antibodies 
against Olfr6/M50, Olfr17/P2, and rat OR-I7 were generated as described previously (Kaneko-Goto et al., 2008).

Immunohistochemistry. Section immunohistochemistry was performed as described previously (Kaneko-Goto et al., 2008). Immunolabeling of olfactory cilia in whole-mount OE preparations was performed as described previously (Strotmann et al., 2004). Primary antibodies used were as follows: rabbit anti-Goofy (1:1000); goat anti-OMP (1:10,000; Wako Pure Chemical Industries); rat anti-NCAM (1:500, Millipore Bioscience Research Reagents); rabbit anti-olfactory cell adhesion molecule (anti-OCAM; 1:1000) (Yoshihara et al., 1997); goat anti-NQO1 (1:500; Abcam); goat anti-neuropilin-1 (1:200; R\&D Systems); goat antineuropilin-2 (1:200; R\&D Systems); goat anti-contactin-4/BIG-2 (1:200; R\&D Systems); rabbit anti-Golf (1:1000; Santa Cruz Biotechnology); rabbit anti-cyclic nucleotide-gated channel A2 subunit (anti-CNGA2; 1:200; Alomone Labs); rabbit anti-ACIII (1:1000; Santa Cruz Biotechnology); rabbit anti-Olfr6/M50 (1:2000); guinea pig anti-Olfr2/I7 (1:2000); guinea pig anti-Olfr17/P2 (1:1000); guinea pig anti-rat OR-I7 (1:5000); guinea pig anti-Olfr73/mOR-EG (1:1000); guinea pig anti-Olfr1507/ MOR28 (1:1000) (Kaneko-Goto et al., 2008). To label intracellular organelles in OSNs, Organelle Sampler Kits (BD Biosciences) and Alexa488-conjugated wheat germ agglutinin (WGA; 1:100; Invitrogen) were used according to the manufacturers' instructions. Cy3-conjugated and Alexa488-conjugated secondary antibodies were purchased from Jackson ImmunoResearch and Invitrogen, respectively. Immunohistochemical analyses were performed on sections $(n=3-10$ mice $)$ and whole-mount $\mathrm{OE}$ ( $n=3-4$ mice) for each antibody.

Western blot analysis. Western blot analysis was performed on olfactory cilia fraction (3 $\mu \mathrm{g}$ of protein/lane), OE homogenate (10 $\mu \mathrm{g}$ of protein/lane), and OB homogenate (10 $\mu \mathrm{g}$ of protein/lane) from $\geq 3$ mice of each genotype as described previously (Kaneko-Goto et al., 2008). Olfactory cilia fraction was prepared by a calcium shock method as described previously (Washburn et al., 2002). Primary antibodies used were as follows: rabbit anti-Goofy (1:1000); rabbit anti-ACIII (1:1000; Santa Cruz Biotechnology). Horseradish peroxidase-conjugated secondary antibodies were purchased from Jackson ImmunoResearch. Immunoreactive protein bands were visualized with a chemiluminescence reaction kit (ECL Plus Western Blotting Detection System, GE Healthcare) and an image analysis system (LAS-1000, Fujifilm).

Transgenic and mutant mice. Goofy-gapVenus transgenic mice were generated with a standard transgenic method. The $3.0 \mathrm{~kb} 5^{\prime}$-flanking region of Goofy gene was PCR-amplified from mouse genomic DNA and inserted into pBstN-gapVenus vector (Mitsui et al., 2011) to generate pGoofy-gapVenus plasmid. Goofy-gapVenus transgene was excised, gelpurified, and injected into the pronucleus of fertilized eggs that were obtained from crossing C57BL/6 and DBA/2J mice. The manipulated eggs were cultured to the two-cell stage and transferred into oviducts of pseudopregnant foster females (ICR strain). Integration of the transgene was screened by PCR of tail DNA.

Goofy-deficient mice were generated with a standard gene-targeting method. Two genomic DNA fragments of mouse Goofy gene $(2.5 \mathrm{~kb}$ SpeI-KpnI short arm and $6.7 \mathrm{~kb}$ XbaI-EcoRI long arm) were subcloned into pSL301 vector (Invitrogen) together with a positive selection marker pgk-neo and a negative selection marker DTA to generate the Goofy targeting vector. Electroporation into 129/SVEv mouse ES cell line followed by G418 selection resulted in four positive homologous recombinants of 288 clones as determined by PCR screening and Southern blot analysis. Chimeric C57BL/6 males that transmitted the mutant allele were obtained, backcrossed with C57BL/6 mice more than nine times, and used for all the experiments.

Generation and characterization of Olfr73(mOR-EG)-ires-gapEGFP transgenic mice were described previously (Oka et al., 2006). I7 (WT)-ires-ECFP and I7(WT)-ires-dnPKA-ires-EYFP transgenic mice (RBRC02931 and RBRC02936) (Imai et al., 2006), generous gifts from Drs. Takeshi Imai and Hitoshi Sakano (The University of Tokyo), were provided by RIKEN Bio Resource Center through the National BioResource Project of the Ministry of Education, Culture, Sports, Science, and Technology (MEXT), Japan.

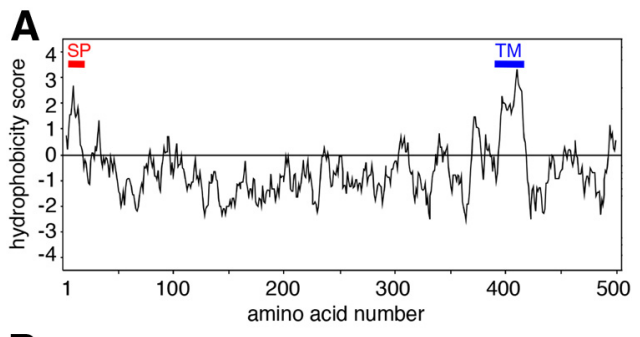

B

1 MQPFSPIFFHLLFLLNGLSSRAAPSPGQPVVADLQGMLQPSGMPTGTLEN

51 LTRDQPTPGSSASHPPEHSETPPSASPHISTKILRETPSPSPFLSLETPI

101 PDQLTSVAESQGTSQMSPSRATLGKPSETPKPDPTGISPSDSPETPKPNP 151 SNTSPPESPESVYTDPTPTLHHESPEISKRDTPKLSPGEESKIPSPRPTQ

201 FLSSKSLETYDPSATRHLNSALEPTTHPDPTESPQSVFLTTHNSNPTVVP 251 QTQFPTSPSQNVTETARTSDLEPSSSLPTQPTTFREEATTPSEPGLSPSP 301 EAPAVTRVATPGLSTSDSPGTKELHVPQNSDPKGPDIPLPSARIAGPPAP 351 LEHPNQVAPAPQRHSRGDTVNTIIVVERVKETGVTLVSRPRGSVGGALCL 401 FFAGTGLLIGIFLLLWCLYRRASRHRSFAHHRLRDSGDEPVLHLDAPKDP 451 LDLYFYAPDAWVPSHIATQPPPSTPPLPPKLPPPPRGPQRLEALSPAALS 501 PNFF

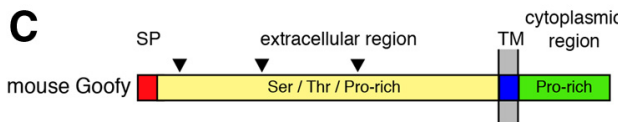

Figure 2. Structure of Goofy protein. $\boldsymbol{A}$, Hydrophobicity plot of mouse Goofy protein. Two highly hydrophobic regions are present: one at the $N$ terminus and the other around amino acid number 400 , which potentially serve as a signal peptide (SP) and a transmembrane segment (TM), respectively. $\boldsymbol{B}$, Amino acid sequence of mouse Goofy protein. Red underline, Signal peptide; blue underline, transmembrane segment; green double underline, canonical SH3binding motif; black triangles, potential Asn-linked glycosylation sites. Ser, Thr, and Pro residues are highlighted in blue, green, and red letters, respectively. C, A schematic diagram depicting the domain structure of Goofy protein. Goofy consists of an N-terminal signal peptide (SP, red), a Ser/Thr/Pro-rich extracellular region (yellow) with three potential glycosylation sites (black triangles), a transmembrane segment (TM, blue), and a Pro-rich cytoplasmic region (green).

Electro-olfactogram recording. Electro-olfactogram (EOG) recording was performed as described previously (Kimoto et al., 2005; Fukuda et al., 2008).

Behavioral analysis. Behavioral responses to 2,4,5-trimethylthiazoline (TMT; Phero Tech) were analyzed as described previously (Kobayakawa et al., 2007) with the following modifications. Group-housed adult male mice (4-6 month old; wild type, $n=36$; Goofy-deficient, $n=35$ ) were used. For habituation to the experimental environment, mice were placed individually in a cage that was identical to the test cage $(14 \times 30 \times$ $20 \mathrm{~cm}$ ). After $30 \mathrm{~min}$, mice were transferred to a new cage. This habituation process was repeated four times for each animal. Then, the mice were transferred to the test cage, and a filter paper $(2 \times 2 \mathrm{~cm})$ scented with various amounts $(0,0.4,4,40 \mu \mathrm{l})$ of TMT was introduced. The test cage was subdivided into two equally sized areas. Time spent in the area without a filter paper was evaluated as avoidance. Freezing time and stay time in each area during the $5 \mathrm{~min}$ test period were measured. The mouse behavior was recorded with a digital video camera (Canon).

\section{Results \\ cDNA cloning and structure of Goofy}

To search for membrane-bound or secreted proteins involved in development and/or function of OSNs, we adopted a yeast signal sequence trap method, which enables us to selectively isolate cDNAs encoding proteins with an N-terminal hydrophobic signal peptide. Poly $(\mathrm{A})+$ RNA was prepared from the OE of $\mathrm{P} 3$ mice and a cDNA library was constructed in a signal sequence trap 

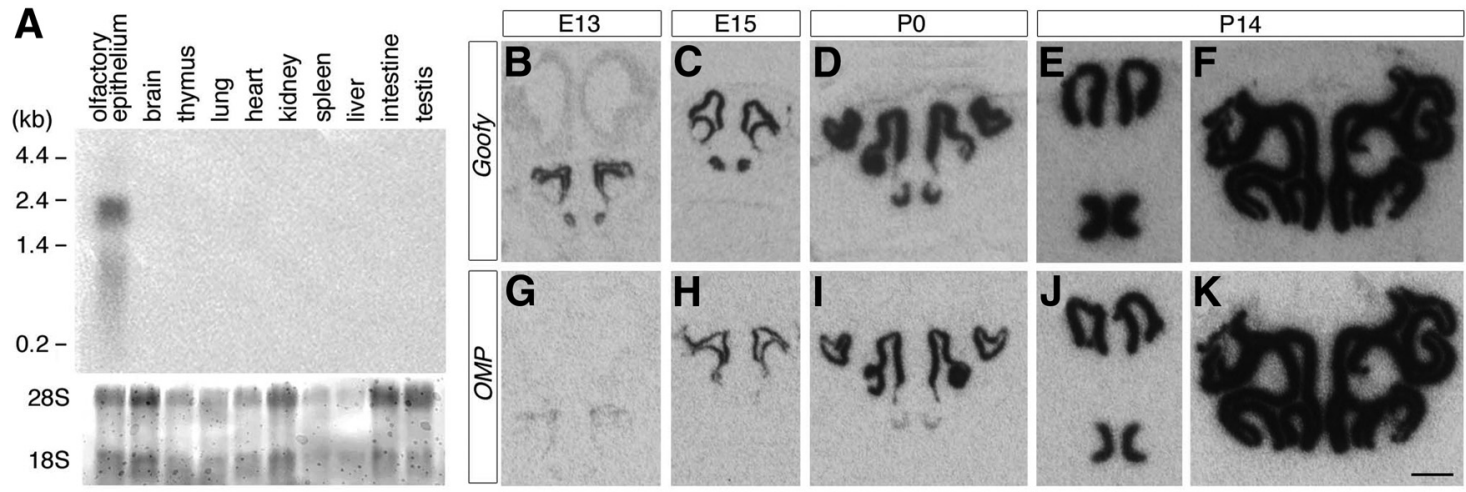

Figure 3. Expression of Goofy mRNA. $A$, Tissue distribution of Goofy mRNA in adult mouse assessed by Northern blot analysis. Top, Autoradiogram of a blot probed with ${ }^{32} \mathrm{P}-$ labeled Goofy cDNA. Bottom, Same blot stained with methylene blue. Goofy mRNA is specifically expressed in the olfactory epithelium. $\boldsymbol{B}-\boldsymbol{K}$, Ontogenic expression of Goofy and OMP mRNAs assessed by in situ hybridization analysis. Coronal sections containing the $0 \mathrm{E}$ and VNO from $\mathrm{E} 13(\boldsymbol{B}, \boldsymbol{G}), \mathrm{E} 15(\boldsymbol{C}, \boldsymbol{H}), \mathrm{PO}(\boldsymbol{D}, \boldsymbol{I})$, and P14 $(\boldsymbol{E}, \boldsymbol{F}, \boldsymbol{J}, \boldsymbol{K})$ mice were hybridized with ${ }^{35} \mathrm{~S}$-labeled $\mathbf{G o o f y}(\boldsymbol{B}-\boldsymbol{F})$ and $0 M P(\boldsymbol{G}-\boldsymbol{K}) \mathrm{CRNA}$ probes. In both $0 \mathrm{E}$ and VNO, the expression of Goofy mRNA precedes that of OMP mRNA. Scale bar: $\boldsymbol{B}-\boldsymbol{K}, 500 \mu \mathrm{m}$.

plasmid (pSUC2T7M13ORI), which harbors a truncated invertase gene without a signal sequence (Jacobs et al., 1997). When the cDNA library was introduced into the invertase-deficient yeast strain YTK12 (total: $1.5 \times 10^{6}$ transformants), only 686 transformants capable of secreting invertase could grow on the glucose-free, raffinose-containing plates, due to in-frame fusion of the truncated invertase with a cDNA-derived signal peptide (Jacobs et al., 1997; Nakashiba et al., 2000). Of the 258 clones sequenced, canonical signal peptides with a stretch of hydrophobic amino acids were present in 215 clones (83.3\%), among which 12 novel genes were included (Fig. 1A,B). Subsequently, we performed in situ hybridization analysis for these genes on mouse head sections (Fig. 1C) and identified the clone \#123 (designated as Goofy) with specific and robust expression in the $\mathrm{OE}$.

The mouse Goofy gene encodes a type I integral membrane protein consisting of an N-terminal signal peptide (21 aa), a long extracellular region (375 aa), a single membrane-spanning domain (23 aa), and a short cytoplasmic region (85 aa) (Fig. 2). The extracellular region of Goofy protein is rich in Ser (15\%), Thr (12\%), and Pro (18\%) residues, contains three potential Asn-linked glycosylation sites, and shows no significant sequence homology to any other proteins. The cytoplasmic region of Goofy is abundant in Pro $(21 \%)$ and contains a canonical SH3-binding motif $(\mathrm{PxxPx}+)$ (Fig. 2B). The Goofy gene appears to be present only in mammalian species, because its orthologs were identified in genomic DNA databases of various mammals, including human, chimpanzee, monkey, dog, cattle, rat, and mouse, but not of nonmammalian organisms, such as chicken, Xenopus, zebrafish, Drosophila, and Caenorhabditis elegans (data not shown).

\section{Expression of Goofy mRNA}

Northern blot analysis was performed to survey the tissue distribution of Goofy mRNA in adult mouse. Goofy mRNA was detected specifically in the OE, but not in other tissues, such as the brain, thymus, lung, heart, kidney, spleen, liver, small intestine, and testis (Fig. $3 A$ ).

Ontogenic expression of Goofy mRNA was investigated by in situ hybridization analysis in comparison with OMP (olfactory marker protein) mRNA, a well characterized molecule expressed in all mature OSNs and VSNs (Margolis et al., 1991; Halpern et al., 1998). Goofy mRNA was first observed at embryonic day (E) 11.5 in the $\mathrm{OE}$ and at E13.5 in the vomeronasal organ (VNO), steadily increased thereafter, reached maximal level at P14, and maintained robust expression level into adulthood (Figs. $1 C, 3 B-F$; data not shown). In contrast, $O M P$ mRNA was first detectable at E15.5 in the OE and postnatally in the VNO (Fig. 3G-K).

These results indicate that the expression of Goofy mRNA is confined to the OE and VNO throughout development and the onset of Goofy expression significantly precedes OMP. 

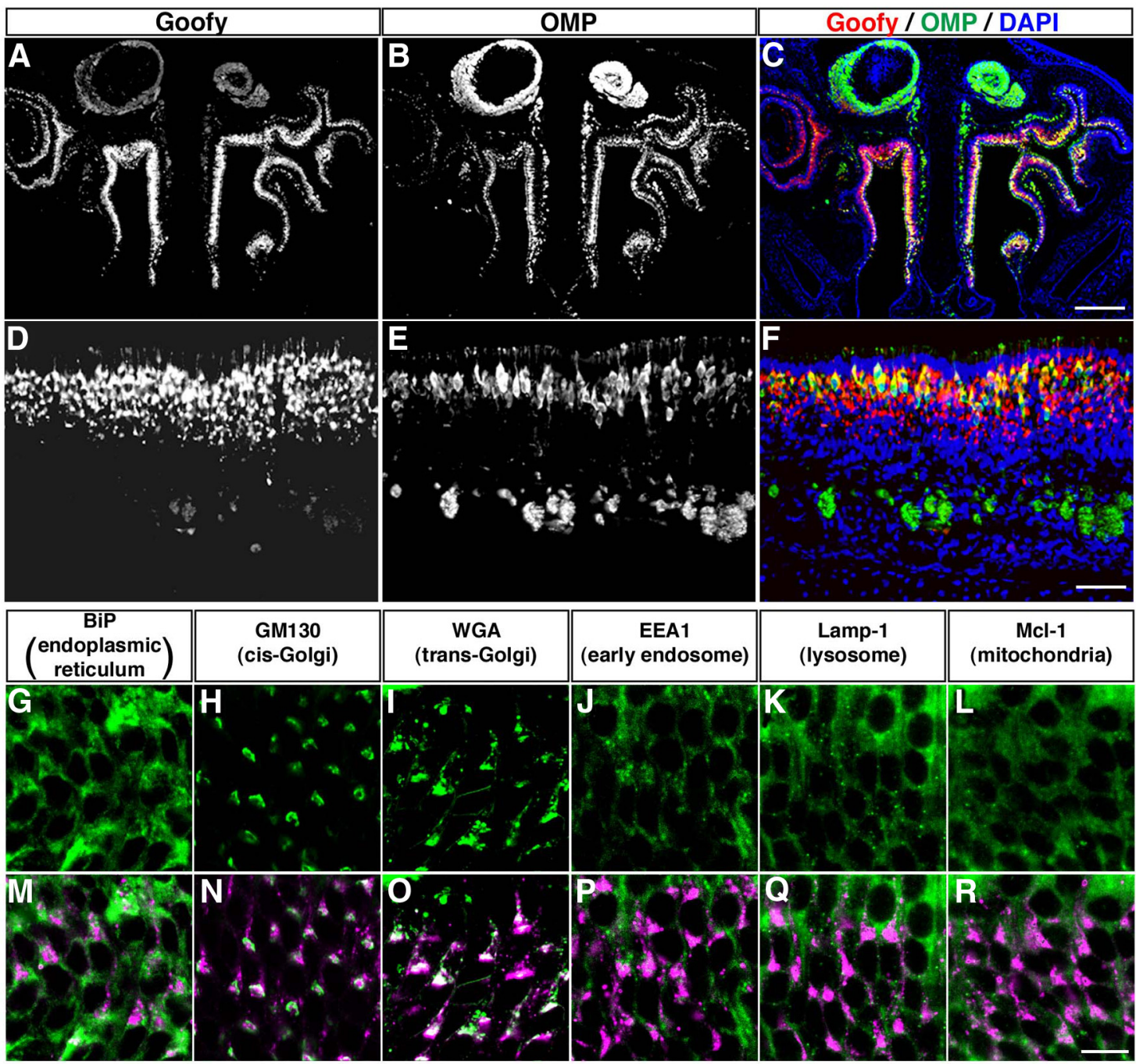

Figure 5. Localization of Goofy protein. $\boldsymbol{A}-\boldsymbol{F}$, Double immun ofluorescence labeling of a coronal section of P3 mouse head with anti-Goofy $(\boldsymbol{A}, \boldsymbol{C}, \boldsymbol{D}, \boldsymbol{F})$ and anti-0MP $(\boldsymbol{B}, \boldsymbol{C}, \boldsymbol{E}, \boldsymbol{F})$ antibodies. $\boldsymbol{D}-\boldsymbol{F}$, Higher magnification of OE. $\boldsymbol{C}, \boldsymbol{F}$, Merged images showing Goofy (red), OMP (green), and DAPI (blue). $\mathbf{G}-\boldsymbol{R}$, Double fluorescence labeling of adult 0 E sections with various organelle markers (green) and anti-Goofy antibody $(\boldsymbol{M}-\boldsymbol{R}$, magenta). The organelle markers include anti-BiP ( $\mathbf{G}, \boldsymbol{M}$, endoplasmic reticulum;), anti-GM130 ( $\boldsymbol{H}, \boldsymbol{N}$, cis-Golgi), WGA $(\boldsymbol{I}, \mathbf{O}$, trans-Golgi), anti-EEA1 (J, $\boldsymbol{P}$, early endosome), anti-Lamp-1 ( $\boldsymbol{K}, \mathbf{Q}$, lysosome), and anti-Mcl-1 ( $\boldsymbol{L}, \boldsymbol{R}$, mitochondria). Goofy is predominantly localized to cis-Golgi and trans-Golgi apparatus $(\boldsymbol{N}, \mathbf{O})$. Reproducibility of the result was confirmed for individual markers in at least three experiments. Scale bars: $\mathbf{A}-\mathbf{C}, 500 \mu \mathrm{m} ; \mathbf{D}-\boldsymbol{F}, 100 \mu \mathrm{m} ; \mathbf{G}-\boldsymbol{R}, 20 \mu \mathrm{m}$.

\section{Promoter analysis of Goofy gene}

The unique expression of Goofy mRNA prompted us to investigate its transcriptional regulatory mechanism. The mouse Goofy gene consists of five exons and four introns that are compactly arranged within $2.5 \mathrm{~kb}$ on the chromosome 7 (Fig. 4A). Intriguingly, the $5^{\prime}$ upstream region of mouse Goofy gene is highly homologous to the previously reported rat DNA sequence 50.06, which was discovered as one of the potential targets of the olfactory transcription factor Olf-1 (Wang and Reed, 1993; Wang et al., 1993). The mouse Goofy gene contains three canonical Olf-1-binding motifs (YTCCCYRGGGAR; Fig. $4 A$, red asterisks) that are commonly present in olfactory neuron-specific genes, such as ORs, Golf, ACIII, CNGA2, and OMP (Wang and Reed, 1993; Wang et al., 1993; Rothman et al., 2005). We constructed a transgene (Goofy-gV) that harbors a $3.0 \mathrm{~kb}$ sequence upstream of the transcriptional start site of Goofy gene, rabbit $\beta$-globin intron, membrane-targeted yellow fluorescence protein (gapVenus) cDNA, and SV40 polyadenylation signal (Fig. 4A).

Eight independent lines of Goofy- $g V$ transgenic mice were established, among which gapVenus transgene was detected specifically in the OE and VNO of six lines (75\%) at different expression levels.
Line \#3 mice showed the strongest fluorescence in olfactory axons projecting from the $\mathrm{OE}$ to the $\mathrm{OB}$, which could be observed in intact E15.5 embryos by epifluorescent stereomicroscopy (Fig. 4B, C). In adults from this line, intense gapVenus fluorescence was detected in the $\mathrm{OE}, \mathrm{VNO}$, and $\mathrm{OB}$, but not in other brain regions or in other tissues (Fig. 4D-G). In addition, we observed gapVenus expression in two other olfactory subsystems: the septal organ and Grueneberg ganglion (data not shown).

These results reinforce the OE-specific and VNO-specific expression of Goofy gene. In addition, the $3.0 \mathrm{~kb}$ upstream region of mouse Goofy gene can be used as an efficient promoter to drive specific and robust expression of transgenes in all types of sensory neurons in the olfactory system.

\section{Localization of Goofy protein}

To address the localization of Goofy protein in the OE, we generated polyclonal antibodies directed against the C-terminal 20 aa peptide of Goofy protein and performed immunohistochemical analysis in comparison with OMP protein, a marker of mature OSNs. On coronal sections of P7 mouse head, both Goofy 

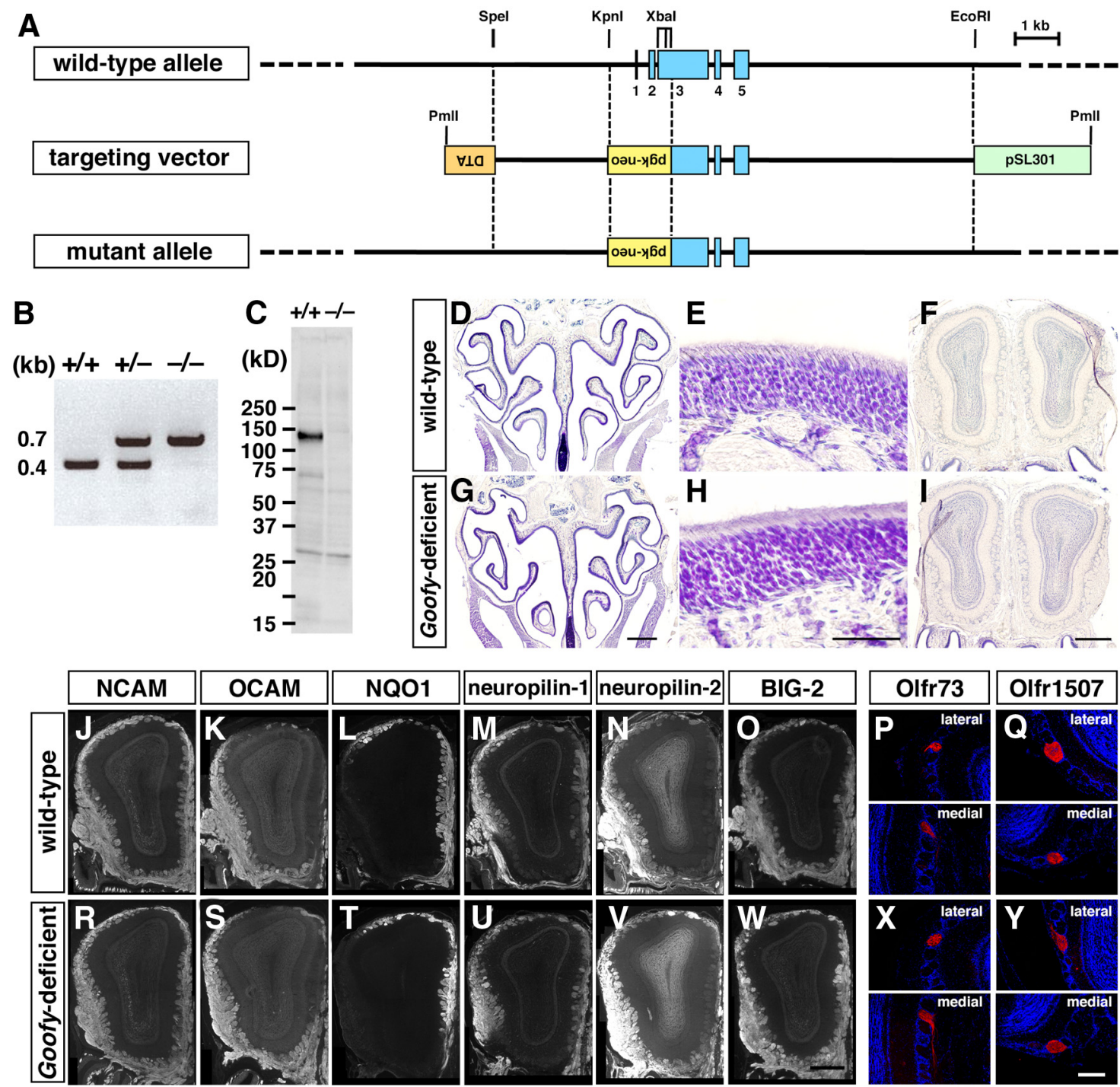

Figure 6. Generation of Goofy-deficient mice. A, Gene targeting strategy to generate Goofy-deficient mice. A pgk-neo selection marker was inserted into the Goofy gene. DTA, Diphtheria toxin A subunit. $\boldsymbol{B}, \mathrm{PCR}$ genotyping of wild-type $(+/+)$, heterozygous $(+/-)$, and homozygous $(-/-)$ mice. $C$, Immunoblot analysis of Goofy protein. Goofy protein is absent in 0 E homogenates from mutant mice. $\boldsymbol{D}-\boldsymbol{I}$, Nissl-stained sections of $0 \mathrm{OE}(\boldsymbol{D}, \boldsymbol{E}, \boldsymbol{G}, \boldsymbol{H})$ and $\mathrm{OB}(\boldsymbol{F}, \boldsymbol{I})$ from wild-type $(\boldsymbol{D}-\boldsymbol{F})$ and Goofy-deficient $(\boldsymbol{G}-\boldsymbol{I})$ mice. No obvious difference in gross anatomy is observed at both low $(\boldsymbol{D}$, $\boldsymbol{F}, \boldsymbol{G}, \boldsymbol{I})$ and high $(\boldsymbol{E}, \boldsymbol{H})$ magnifications. $\boldsymbol{J}-\boldsymbol{Y}$, Immunofluorescence labeling of OB sections from wild-type $(\boldsymbol{J}-\boldsymbol{Q})$ and Goofy-deficient $(\boldsymbol{R}-\boldsymbol{Y})$ mice with antibodies against NCAM $(\boldsymbol{J}, \boldsymbol{R}), \mathbf{O C A M}(\boldsymbol{K}, \boldsymbol{S})$, NQ01 $(\boldsymbol{L}, \boldsymbol{T})$, neuropilin-1 $(\boldsymbol{M}, \boldsymbol{U})$, neuropilin-2 $(\boldsymbol{N}, \boldsymbol{V}), \mathrm{BIG}-2(\mathbf{O}, \boldsymbol{W}), \mathbf{O l f r} 73(\boldsymbol{P}, \boldsymbol{X})$, and 0 lff1507 $(\boldsymbol{Q}, \boldsymbol{Y})$. No difference is observed in the expression of cell adhesion molecules $(\boldsymbol{J}-\mathbf{0}, \boldsymbol{R}-\boldsymbol{W})$ and the olfactory axon convergence to both lateral and medial target glomeruli $(\boldsymbol{P}, \mathbf{Q}, \mathbf{X}, \mathbf{Y})$. Scale bars: $\mathbf{D}, \mathbf{G}, \mathbf{J}-\mathbf{O}, \boldsymbol{R}-\boldsymbol{W}, 500 \mu \mathrm{m} ; \boldsymbol{E}, \boldsymbol{H}, \mathbf{P}, \mathbf{Q}, \mathbf{X}, \mathbf{Y}, 200 \mu \mathrm{m}$.

and OMP proteins were present throughout the OE with no zonal preference (Fig. $5 A-C$ ). Higher-magnification views revealed that Goofy protein was expressed in both immature and mature OSNs and most abundantly localized to the cell bodies, while OMP protein was present only in mature OSNs and showed cytoplasmic localization with an almost equal level of immunoreactivity in cell bodies, dendrites, and axons (Fig. 5D-F). Goofy protein was not detected in the globose and horizontal basal cells that are located in the most basal region of $\mathrm{OE}$.

The intracellular localization of Goofy protein in OSNs was examined by double fluorescence labeling with various organelle markers. Goofy protein was colocalized almost perfectly with GM130 (cis-Golgi marker) and WGA (trans-Golgi marker) and partially with BiP (endoplasmic reticulum marker), but not with EEA1 (early endosome marker), Lamp-1 (lysosome marker), and Mcl-1 (mitochondria marker; Fig. 5G-R).

These results indicate that Goofy protein is predominantly localized to the Golgi apparatus in both immature and mature
OSNs. A similar Golgi apparatus-specific localization of Goofy protein was also observed in the sensory neurons of the VNO (both apical and basal zones), septal organ, and Grueneberg ganglion, as well as in Goofy cDNA-transfected N2a cells (data not shown).

\section{Abnormal localization of ACIII in Goofy-deficient mice}

To elucidate the physiological function of Goofy, we generated Goofy-deficient mice by disrupting the noncoding exons 1 and 2 and a part of exon 3, which encodes the signal peptide of Goofy protein (Fig. $6 A, B$ ). The absence of Goofy protein in the mutant mice was validated by Western blot and immunohistochemical analyses (Figs. 6C, 7 A,F). Gross anatomy and layer organization of $\mathrm{OE}$ and $\mathrm{OB}$ in Goofy-deficient mice were not different from those of wild-type mice, as assessed by Nissl staining (Fig. 6D-I). The olfactory axon wiring from the OE to the OB appeared normal in Goofy-deficient mice, as assessed by both the differential expression patterns of various axon guidance molecules (e.g., 


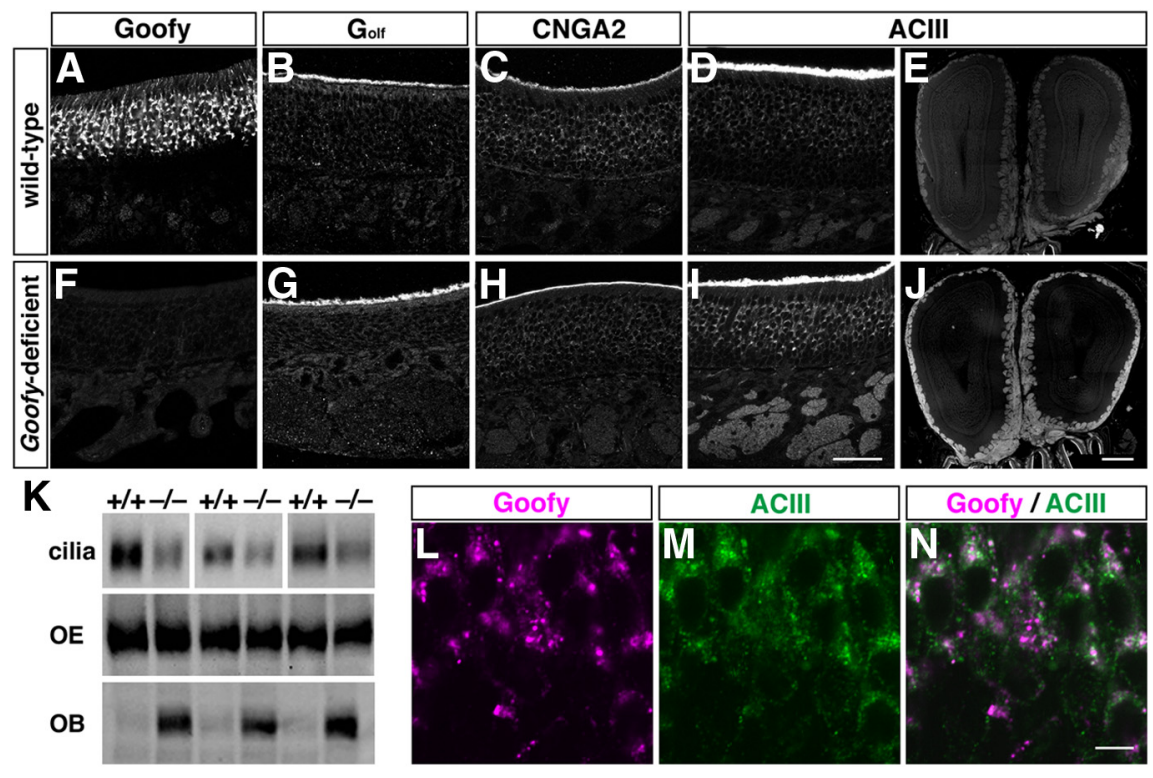

Figure 7. Abnormal localization of ACIII in Goofy-deficient mice. $\boldsymbol{A}-\boldsymbol{J}$, Immunofluorescence labeling of $O E(\boldsymbol{A}-\boldsymbol{D}, \boldsymbol{F}-\boldsymbol{I})$ and $O B$ $(\boldsymbol{E}, \boldsymbol{J})$ sections with antibodies against $\operatorname{Goofy}(\boldsymbol{A}, \boldsymbol{F})$, Golf $(\boldsymbol{B}, \boldsymbol{G}), \mathrm{CNGA2}(\boldsymbol{C}, \boldsymbol{H})$, and $A C I I I(\boldsymbol{D}, \boldsymbol{E}, \boldsymbol{I}, \boldsymbol{J})$. In wild-type mice, Golf, CNGA2, and $A C I I I$ are highly localized to olfactory cilia, while strong ACIII immunoreactivity is observed also in olfactory axons and glomeruli of mutant mice. $\boldsymbol{K}$, Immunoblot analysis of $\mathrm{ACIII}$ protein in olfactory cilia, whole $\mathrm{OE}$, and $\mathrm{OB}$ from three individual mice of each genotype. In Goofy-deficient mice, ACIII is significantly decreased in the cilia (60 $\pm 7 \%$ ), slightly decreased in the $0 \mathrm{E}(94 \pm 2 \%)$, and dramatically increased in the OB $(496 \pm 41 \%)$, compared with wild-type mice $(n=3)$. $L-N$, Double immunofluorescence labeling of wild-type 0 E section with anti-Goofy $(\boldsymbol{L}, \boldsymbol{N})$ and anti-ACIII $(\boldsymbol{M}, \boldsymbol{N})$ antibodies. $\boldsymbol{N}$, A merged image showing colocalization of Goofy (magenta) and ACIII (green) at Golgi apparatus in OSNs. Scale bars: $\boldsymbol{A}-\boldsymbol{D}, \boldsymbol{F}-\boldsymbol{I}, 200 \mu \mathrm{m} ; \boldsymbol{E}, \boldsymbol{J}, 500 \mu \mathrm{m} ; \boldsymbol{L}-\boldsymbol{N}, 20 \mu \mathrm{m}$.

nating from dendritic knobs of OSNs (Fig. $8 A)$. In contrast, the length of Olfr2positive and Olfr6-positive cilia appeared markedly shorter in Goofy-deficient OE (Fig. $8 B$ ). To verify whether the use of OR antibodies is sufficient to assess the cilia length, we used Olfr73-ires-gapEGFP transgenic mice in which membranetethered GFP is expressed in Olfr73expressing OSNs (Oka et al., 2006). Double immunofluorescence labeling of $\mathrm{OE}$ sections of Olfr73-ires-gapEGFP mice on Goofy-deficient background revealed that Olfr73 signals in olfactory cilia almost completely overlapped with GFP signals (Fig. $8 C-E$ ). Thus, OR proteins are properly trafficked even to the most distal part of olfactory cilia, validating the appropriateness of using OR antibodies for assessment of the cilia length. When the OE sections of wildtype and Goofy-deficient mice were immunostained with anti-Olfr2, anti-Olfr17, and anti-Olfr73 antibodies, a clear difference was observed in the extent of cilial coverage of individual OSNs on OE surface (Fig. $8 F-$ $K)$. Quantification of cilia length revealed that the olfactory cilia in Goofy-deficient mice were significantly shorter than those in wild-type mice for all three OR-expressing OSNs examined (Fig. $8 L-N$ ).

NCAM, OCAM, NQO-1, neuropilin-1, neuropilin-2, BIG-2, kirrel 2) and the convergence of particular OR-expressing OSNs to their target glomeruli (e.g., Olfr73 [mOR-EG], Olfr1507 [MOR28], and Olfr2 [I7]) (Fig. 6J-Y; data not shown). Furthermore, no obvious change was detected in expression patterns of various functional molecules in OSNs, such as Golf, CNGA2, NKCC1, and OMP (Fig. $7 B, C, G, H$; data not shown).

However, we noticed abnormal localization of ACIII in OSNs of Goofy-deficient mice. In wild-type mice, ACIII was predominantly localized to the olfactory cilia where the odorant-induced signal transduction occurs through sequential activation of ORs, Golf, ACIII, and a cyclic nucleotide-gated cation channel. In Goofy-deficient mice, however, a high level of ACIII immunoreactivity was observed not only in the olfactory cilia and cell bodies, but also in axons innervating $\mathrm{OB}$ glomeruli (Fig. $7 \mathrm{D}, E, I, J$ ). Western blot analysis also revealed the abnormal localization of ACIII in Goofy-deficient mice with a substantial decrease in the olfactory cilia ( $60 \pm 7 \%$ of wild-type mice) and a drastic increase in the OB $(496 \pm 41 \%$ of wild-type mice) (Fig. $7 K)$. A highmagnification image of wild-type OE revealed that Goofy and ACIII proteins are colocalized in Golgi apparatus of OSNs (Fig. $7 L-N)$. These results suggest that the intracellular trafficking of ACIII from Golgi apparatus to olfactory cilia is impaired in Goofy-deficient mice.

\section{Shortened olfactory cilia in Goofy-deficient mice}

Next, we compared the OR protein localization in OSNs between wild-type and Goofy-deficient mice. Specific antibodies recognizing four well characterized OR proteins were used for this analysis: anti-Olfr2 (I7), anti-Olfr6 (M50), anti-Olfr17 (P2), and anti-Olfr73 (mOR-EG) (Kaneko-Goto et al., 2008). By wholemount immunofluorescence labeling of wild-type OE, Olfr2 and Olfr6 proteins were clearly detectable on the olfactory cilia ema-
In various cell types, the length of primary cilia is regulated through the cAMP signaling pathway. Elevation of intracellular cAMP levels results in the elongation of primary cilia, whereas decreased cAMP leads to cilium shortening (Besschetnova et al., 2010; Abdul-Majeed et al., 2012). Because the olfactory cilia are classified as a specialized form of the primary cilia (Singla and Reiter, 2006; Berbari et al., 2009), it is conceivable that the cAMP signaling may also control cilia length in the OSNs. To address this possibility, we analyzed two lines of transgenic mice, $I 7(W T)$ ires-ECFP and I7(WT)-ires-dnPKA-ires-EYFP), in which rat OR-I7 is expressed in a small population of OSNs with or without the dominant-negative form of CAMP-dependent protein kinase (dnPKA), respectively (Imai et al., 2006). Immunofluorescent labeling of OE sections with rat OR-I7-specific antibody revealed that the length of olfactory cilia was greatly shortened in the dnPKA-expressing OSNs, compared with the control OSNs (Fig. $80-Q)$. These results suggest the role of cAMP as a regulator of ciliogenesis in OSNs, implying a possible mechanistic link between the mislocalized ACIII and the shortened olfactory cilia in Goofy-deficient mice.

\section{Reduced olfactory sensitivity in Goofy-deficient mice}

The above observation of shortened olfactory cilia led us to examine whether the Goofy deficiency results in impairment of odor-induced physiological and behavioral responses. To evaluate the physiological responses of OSNs, local field potentials (EOG) were recorded from the epithelial surface using intact $O E$ preparations of wild-type and Goofy-deficient mice. The EOG responses to various odorants (eugenol, 2-heptanone, 1-heptanol, safrole, and lilial) were smaller in Goofy-deficient mice than in wild-type mice (Fig. 9A, $B$; data not shown). A concentration-response curve for eugenol demonstrates a clear difference of EOG amplitudes between the two genotypes 
(Fig. 9C). Thus, Goofy-deficient OSNs displayed reduced sensitivity to odorants.

Finally, olfactory behaviors were compared between wild-type and Goofydeficient mice. We used TMT (a component of fox feces odor) as a stimulus odorant, which evokes innate fear responses in rodents (Varnet-Maury et al., 1984; Fendt et al., 2005). TMT exposure induced avoidance and freezing responses in both wild-type and Goofy-deficient mice in a dose-dependent manner, but their sensitivities to TMT were clearly different (Fig. $9 D, E)$. Wild-type mice showed significant responses even at the lowest amount (0.4 $\mu \mathrm{l})$ of TMT. In contrast, the response threshold to TMT was higher in Goofydeficient mice, with smaller values of avoidance index and shorter durations of freezing time to the lowest and middle amounts. At the highest amount of TMT, however, there was no difference in the responses between the two genotypes.

Thus, the electrophysiological and behavioral analyses revealed that the olfactory sensitivity of Goofy-deficient mice is significantly lower than that of wild-type mice, suggesting that mice become "dullnosed" without Goofy function.

\section{Discussion}

We discovered a novel membrane protein Goofy that is specifically expressed in OSNs and VSNs and predominantly localized to the Golgi apparatus. The Goofydeficient mice displayed various olfactory phenotypes, such as abnormal localization of ACIII, shortened olfactory cilia, and reduced electrophysiological and behavioral sensitivities to odorants. These findings demonstrate that Goofy is a crucial molecule for proper function of the olfactory system.

Northern blot, in situ hybridization, and immunohistochemical analyses revealed that Goofy mRNA and its translation product are expressed by sensory neurons of the olfactory system in a highly restricted manner. This rigorous regulation of Goofy gene transcription was verified by generating transgenic mice in which a fluorescent reporter protein was strongly and specifically expressed in the $\mathrm{OE}, \mathrm{VNO}$, septal organ, and Grueneberg ganglion under the control of Goofy gene promoter encompassing the $3 \mathrm{~kb}$ upstream sequence. The mouse Goofy gene contains three Olf-1-binding sites with a consensus nucleotide sequence of YTCCCYRGGGAR. Olf-1, also known as early B-cell factor-1, was first identified in rats as an olfactory neuron-specific transcription factor that binds to the conserved cis-acting regulatory elements commonly present upstream of ORs, OMP, Golf, ACIII, and CNGA2 as well as two functionally uncharacterized genes 50.06 and 50.11 (Wang and Reed, 1993; Q,50 $\mu \mathrm{m}$.
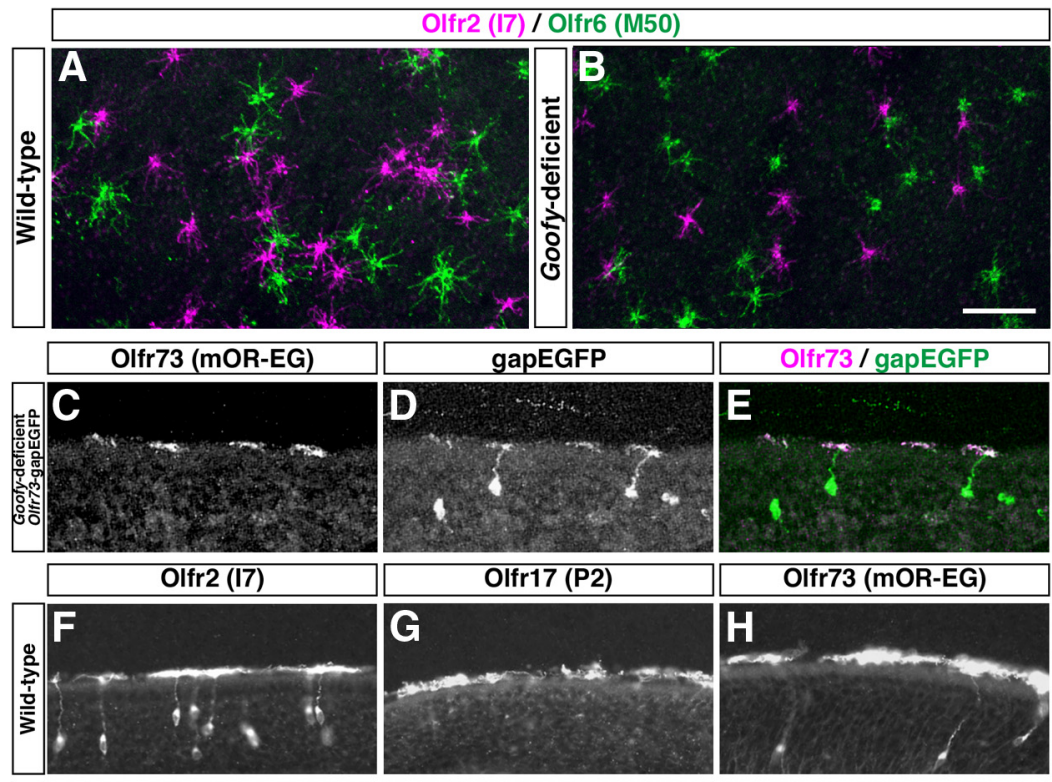

Olfr73 (mOR-EG)
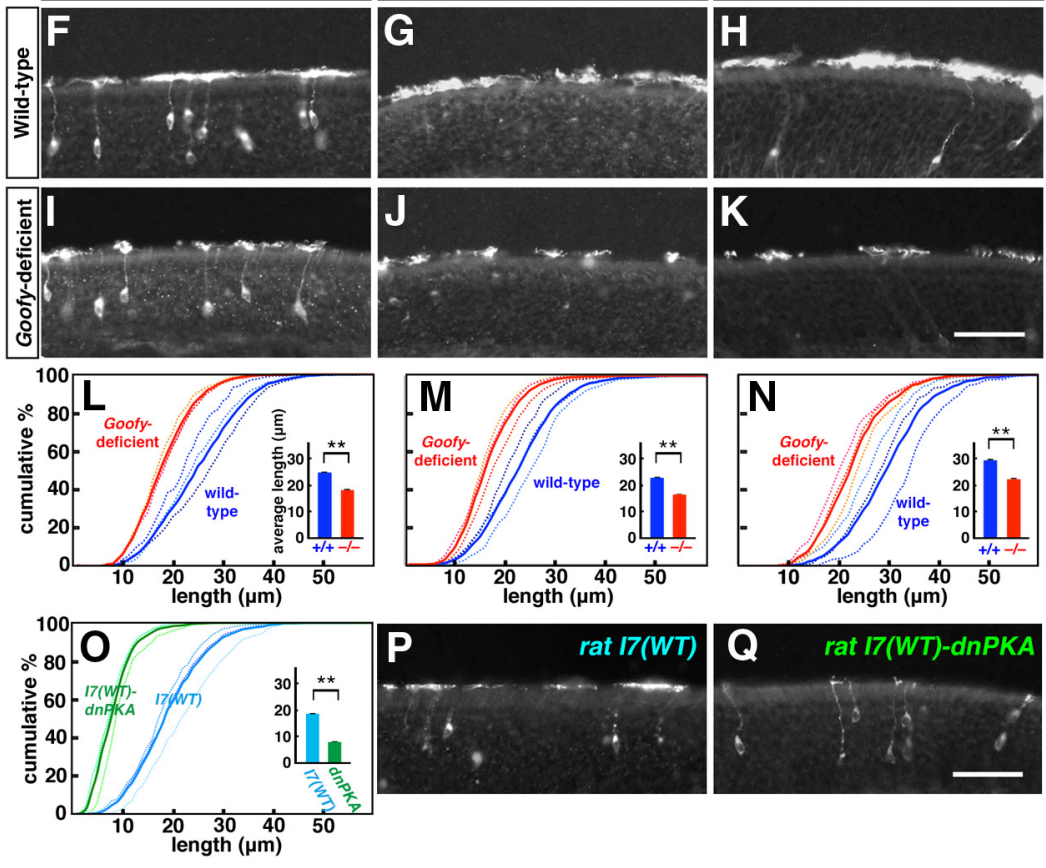

Figure 8. Shortened olfactory cilia in Goofy-deficient mice and dnPKA-expressing transgenicmice. $\boldsymbol{A}, \boldsymbol{B}$, Whole-mount 0 Epreparations from wild-type $(\boldsymbol{A})$ and Goofy-deficient $(\boldsymbol{B})$ mice immunolabeled with anti-0lfr2 (17, magenta) and anti-0lfr6 (M50, green) antibodies. The length of both Olfr2-expressing and Olfr6-expressing olfactory cilia in Goofy-deficient mice is markedly shorter than that in wild-type mice. $\boldsymbol{C}-\boldsymbol{E}$, Double immunofluorescence labeling of an OE section from Olfr73-ires-gapEGFP transgenic mouse on Goofy-deficient background with anti-0lfr73 $(\boldsymbol{C}, \boldsymbol{E})$ and anti-GFP $(\boldsymbol{D}, \boldsymbol{E})$ antibodies. $\boldsymbol{E}$, A merged image showing perfect overlapping of 0lfr73 (magenta) with GFP (green) in the olfactory cilia. $\boldsymbol{F}-\boldsymbol{K}$, Immunofluorescence labeling of $0 \mathrm{E}$ sections from wild-type $(\boldsymbol{F}-\boldsymbol{H})$ and $G$ oofy-deficient $(\boldsymbol{I}-\boldsymbol{K})$ mice with antibodies against Olfr2 (I7; $\boldsymbol{F}, \boldsymbol{I}), 0$ lfr17 (P2; $\boldsymbol{G}, \boldsymbol{J})$, and Olfr73 (mOR-EG; $\boldsymbol{H}, \boldsymbol{K})$. $\boldsymbol{L}-\boldsymbol{N}$, Cumulative frequency plot for length of olfactory cilia expressing 0 lfr2 $(\boldsymbol{L}), 0$ lfr17 $(\boldsymbol{M})$, and 01 fr73 $(\boldsymbol{N})$ in wild-type (blue) and Goofy-deficient (red) mice. Thin broken lines represent the results from individual mice ( $n=3$ mice for each genotype; $n=259-805$ OSNs for each mouse), while bold lines represent pooled data ( $n=$ $1196-1815$ OSNs). Insets, Averages of cilia length. For all the three ORs, the length of olfactory cilia in Goofy-deficient mice is significantly shorter than that in wild-type mice. 0, Cumulative frequency plot for length of rat I7-expressing olfactory cilia in /7-ires-ECFP(light blue) and 17-ires-dnPKA-ires-EYFP (green) transgenic mice. Thin broken lines represent the results from individual mice ( $n=3$ mice for each genotype; $n=292-693$ OSNs for each mouse), while bold lines represent pooled data ( $n=1538$ for 17 -ires-ECFP; $n=1229$ for 17 -iresdnPKA-ires-EYFP). Insets, Averages of cilia length. $\boldsymbol{P}, \boldsymbol{Q}$, Immunofluorescence labeling of coronal sections of 0 E from 17 -ires-ECFP $(\boldsymbol{P})$ and 17-ires-dnPKA-ires-EYFP(Q) transgenic mice with anti-rat I7-specific antibody. ${ }^{* *} p<0.01$ (2-tailed ttest). Scale bars: $\boldsymbol{A}, \boldsymbol{B}, 20 \mu \mathrm{m} ; \boldsymbol{C}-\boldsymbol{K}, \boldsymbol{P}$,

Wang et al., 1993). Although the following studies reported that the 50.11 gene encodes an olfactory signal-modulating protein, SLP3/SRO, belonging to the stomatin family (Kobayakawa et al., 2002; Goldstein et al., 2003), the functional role of 50.06 gene product remained to be elucidated. Interestingly, the reported nucleotide sequence $(1.0 \mathrm{~kb})$ in the $5^{\prime}$-upstream region of rat 50.06 gene (Wang et al., 1993) is highly homologous to that of mouse Goofy gene with $86 \%$ identity. This significant sequence 

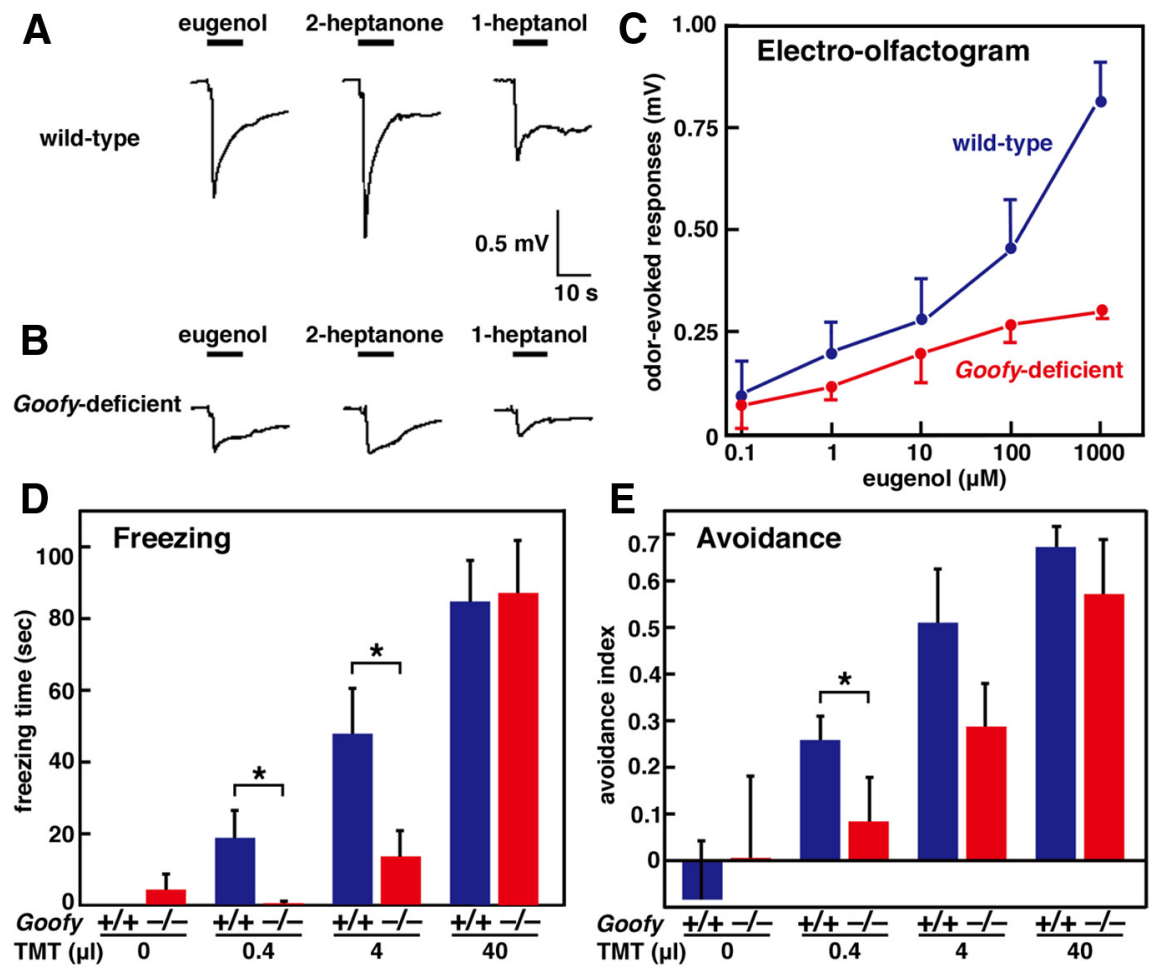

Figure 9. Reduced olfactory sensitivity in Goofy-deficient mice. $A-C$, Electrophysiological properties of OSN sassessed by measurement of odor-evoked EOG responses $(\boldsymbol{A}, \boldsymbol{B})$. Representative EOG traces to eugenol, 2-heptanone, and 1-heptanol in wild-type $(\boldsymbol{A})$ and Goofydeficient $(\boldsymbol{B})$ mice. C, Relationship between applied eugenol concentrations and EO G responses in wild-type (blue) and Goofy-deficient(red) mice ( $n=12$ for each genotype). ${ }^{*} p<0.05$ (2-tailed $t$ test). D, E, Behavioral responses of wild-type (blue) and Goofy-deficient (red) mice to an aversive odor TMT stimulation ( $n=8-10$ for each genotype and each TMT concentration). Freezing time ( $\boldsymbol{D})$ and avoidance index $(\boldsymbol{E})$ were measured for the two genotypes to different amounts of TMT. ${ }^{*} p<0.05$ (Mann-Whitney $U$ test).

homology indicates that the 50.06 gene encodes a rat ortholog of Goofy and that Olf-1 plays a crucial role in regulating the restricted expression of Goofy/50.06 in rodent olfactory neurons.

Another remarkable feature of Goofy expression is its early appearance in both developmental and differentiation aspects in sharp contrast to the later onset of OMP expression. Ontogenic analysis revealed that Goofy mRNA is detectable as early as at E11.5 in the OE and at E13.5 in the VNO, much earlier than the appearance of $O M P$. In the neonates and adults, Goofy protein is present in both the immature and mature OSNs residing in the deep and superficial layers of OE, respectively, but not in the globose or horizontal basal cells, the progenitors of OSNs and sustentacular cells (Schwob, 2002). Thus, the Goofy expression starts at a postmitotic, immature stage during the differentiation process of OSNs.

For the OSN-specific transgene expression, the transcriptional regulatory region of OMP gene has been widely used so far (Mombaerts et al., 1996; Walters et al., 1996; Yoshihara et al., 1999; Bozza et al., 2004; Nguyen et al., 2007). Although the OMP gene promoter/enhancer has proved powerful in many cases, it can drive transgene expression only in the mature OSNs. In contrast, the present study demonstrates that the $3 \mathrm{~kb}$ fragment upstream of mouse Goofy gene can efficiently induce transgene expression in both the immature and mature OSNs from developmental stages earlier than the expression onset of OMP and other olfactory signaling molecules. Thus, the Goofy gene promoter/enhancer will become a useful and convenient tool for various studies on differentiation, maturation, and function of OSNs.

Immunohistochemical analysis with various organelle markers revealed that Goofy protein is predominantly localized to
Golgi apparatus of OSNs. The Golgi apparatus is an intracellular central organelle with a well established role as a processing and sorting station in the transport of secretory and transmembrane cargo proteins to their final destination (Wilson et al., 2011). By surveying the expression patterns of various functional molecules in OSNs, we found the abnormal localization of ACIII, an enzyme playing a pivotal dual role in odor-induced signal transduction cascade (Bakalyar and Reed, 1990) and olfactory axon targeting to OB (Imai et al., 2006). ACIII is a transmembrane protein normally highly enriched in olfactory cilia (Bakalyar and Reed, 1990). In Goofy-deficient mice, however, ACIII was also abundantly detected in olfactory axons and glomeruli. Thus, it is likely that Goofy associates with ACIII in Golgi apparatus of OSNs, regulating either its post-translational modification or intracellular trafficking. Further biochemical and proteomics analyses are now in progress to gain mechanistic insight into the interaction between Goofy and ACIII as well as to search for other functional molecules that associate with Goofy.

In addition to this molecular phenotype of ACIII mislocalization, Goofydeficient mice displayed morphological abnormality of OSNs: the shortening of olfactory cilia. How does Goofy protein in the Golgi apparatus affect the morphology of olfactory cilia? We observed that the length of olfactory cilia is drastically shortened by the transgenic expression of dnPKA, suggesting a crucial role of cAMP signaling in ciliogenesis of OSNs. A similar regulatory mechanism of olfactory cilia architecture by cyclic nucleotide was reported in C. elegans, where cGMP signaling plays an important role (Mukhopadhyay et al., 2008). Taking into consideration all of these findings, we speculate that the abnormal localization of ACIII in Goofy-deficient mice might cause insufficiency of cAMP production in dendrites, resulting in the impaired elongation of olfactory cilia. Consequently, Goofy-deficient mice may display reduced sensitivity to odorants in both physiological and behavioral analyses, rendering themselves goofy-nosed.

The cAMP second messenger system appears to play three important roles in OSN functioning: odor-induced neuronal excitation (Bakalyar and Reed, 1991; Schild and Restrepo, 1998), olfactory axon guidance (Imai et al., 2006; Col et al., 2007), and ciliogenesis (this study). In Goofy-deficient mice, the odorinduced responses were smaller and the olfactory cilia were shorter than in wild-type mice, whereas the olfactory axon projection to target glomeruli appeared normal. It is likely that the degree of odor-induced activation and the length of olfactory cilia are attributable to the absolute cAMP level in individual OSNs in a cell-autonomous manner. In contrast, the olfactory axon innervation may be determined by the relative difference in cAMPregulated expression levels of axon guidance molecules among distinct OR-expressing OSNs (Mori and Sakano, 2011). Therefore, it is conceivable that the olfactory axons can precisely innervate target glomeruli in appropriate OB regions in Goofy- 
deficient mice where cAMP signaling cascade is partially toned down in all OSNs evenly.

\section{References}

Abdul-Majeed S, Moloney BC, Nauli SM (2012) Mechanisms regulating cilia growth and cilia function in endothelial cells. Cell Mol Life Sci 69: 165-173. CrossRef Medline

Axel R (1995) The molecular logic of smell. Sci Am 273:154-159. CrossRef Medline

Bakalyar HA, Reed RR (1990) Identification of a specialized adenylyl cyclase that may mediate odorant detection. Science 250:1403-1406. CrossRef Medline

Bakalyar HA, Reed RR (1991) The second messenger cascade in olfactory receptor neurons. Curr Opin Neurobiol 1:204-208. CrossRef Medline

Berbari NF, O'Connor AK, Haycraft CJ, Yoder BK (2009) The primary cilium as a complex signaling center. Curr Biol 19:R526-R535. CrossRef Medline

Besschetnova TY, Kolpakova-Hart E, Guan Y, Zhou J, Olsen BR, Shah JV (2010) Identification of signaling pathways regulating primary cilium length and flow-mediated adaptation. Curr Biol 20:182-187. CrossRef Medline

Bozza T, McGann JP, Mombaerts P, Wachowiak M (2004) In vivo imaging of neuronal activity by targeted expression of a genetically encoded probe in the mouse. Neuron 42:9-21. CrossRef Medline

Buck L, Axel R (1991) A novel multigene family may encode odorant receptors: a molecular basis for odorant recognition. Cell 65:175-187. CrossRef Medline

Buck LB (2000) The molecular architecture of odor and pheromone sensing in mammals. Cell 100:611-618. CrossRef Medline

Col JA, Matsuo T, Storm DR, Rodriguez I (2007) Adenylyl cyclasedependent axonal targeting in the olfactory system. Development 134: 2481-2489. CrossRef Medline

Dhallan RS, Yau KW, Schrader KA, Reed RR (1990) Primary structure and functional expression of a cyclic nucleotide-activated channel from olfactory neurons. Nature 347:184-187. CrossRef Medline

Fendt M, Endres T, Lowry CA, Apfelbach R, McGregor IS (2005) TMTinduced autonomic and behavioral changes and the neural basis of its processing. Neurosci Biobehav Rev 29:1145-1156. CrossRef Medline

Fukuda N, Shirasu M, Sato K, Ebisui E, Touhara K, Mikoshiba K (2008) Decreased olfactory mucus secretion and nasal abnormality in mice lacking type 2 and type 3 IP3 receptors. Eur J Neurosci 27:2665-2675. CrossRef Medline

Gibson AD, Garbers DL (2000) Guanylyl cyclases as a family of putative odorant receptors. Annu Rev Neurosci 23:417-439. CrossRef Medline

Goldstein BJ, Kulaga HM, Reed RR (2003) Cloning and characterization of SLP3: a novel member of the stomatin family expressed by olfactory receptor neurons. J Assoc Res Otolaryngol 4:74-82. Medline

Halpern M, Jia C, Shapiro LS (1998) Segregated pathways in the vomeronasal system. Microsc Res Tech 41:519-529. CrossRef Medline

Imai T, Suzuki M, Sakano H (2006) Odorant receptor-derived cAMP signals direct axonal targeting. Science 314:657-661. CrossRef Medline

Jacobs KA, Collins-Racie LA, Colbert M, Duckett M, Golden-Fleet M, Kelleher K, Kriz R, LaVallie ER, Merberg D, Spaulding V, Stover J, Williamson MJ, McCoy JM (1997) A genetic selection for isolating cDNAs encoding secreted proteins. Gene 198:289-296. CrossRef Medline

Jones DT, Reed RR (1989) Golf: an olfactory neuron specific-G protein involved in odorant signal transduction. Science 244:790-795. CrossRef Medline

Kaneko-Goto T, Yoshihara S, Miyazaki H, Yoshihara Y (2008) BIG-2 mediates olfactory axon convergence to target glomeruli. Neuron 57:834-846. CrossRef Medline

Kimoto H, Haga S, Sato K, Touhara K (2005) Sex-specific peptides from exocrine glands stimulate mouse vomeronasal sensory neurons. Nature 437:898-901. CrossRef Medline

Kobayakawa K, Hayashi R, Morita K, Miyamichi K, Oka Y, Tsuboi A, Sakano H (2002) Stomatin-related olfactory protein, SRO, specifically expressed in the murine olfactory sensory neurons. J Neurosci 22: 5931-5937. Medline

Kobayakawa K, Kobayakawa R, Matsumoto H, Oka Y, Imai T, Ikawa M, Okabe M, Ikeda T, Itohara S, Kikusui T, Mori K, Sakano H (2007) Innate versus learned odour processing in the mouse olfactory bulb. Nature 450:503-508. CrossRef Medline
Margolis FL, Verhaagen J, Biffo S, Huang FL, Grillo M (1991) Regulation of gene expression in the olfactory neuroepithelium: a neurogenetic matrix. Prog Brain Res 89:97-122. CrossRef Medline

McEwen DP, Jenkins PM, Martens JR (2008) Olfactory cilia: our direct neuronal connection to the external world. Curr Top Dev Biol 85:333-370. CrossRef Medline

Mitsui S, Igarashi KM, Mori K, Yoshihara Y (2011) Genetic visualization of the secondary olfactory pathway in Tbx21 transgenic mice. Neural Syst Circuits 1:5. CrossRef Medline

Mombaerts P, Wang F, Dulac C, Chao SK, Nemes A, Mendelsohn M, Edmondson J, Axel R (1996) Visualizing an olfactory sensory map. Cell 87:675-686. CrossRef Medline

Mori K, Sakano H (2011) How is the olfactory map formed and interpreted in the mammalian brain? Ann Rev Neurosci 34:467-499. CrossRef Medline

Mori K, Nagao H, Yoshihara Y (1999) The olfactory bulb: coding and processing of odor molecule information. Science 286:711-715. CrossRef Medline

Mukhopadhyay S, Lu Y, Shaham S, Sengupta P (2008) Sensory signalingdependent remodeling of olfactory cilia architecture in C. elegans. Dev Cell 14:762-774. CrossRef Medline

Nakashiba T, Ikeda T, Nishimura S, Tashiro K, Honjo T, Culotti JG, Itohara S (2000) Netrin-G1: a novel glycosyl phosphatidylinositol-linked mammalian netrin that is functionally divergent from classical netrins. J Neurosci 20:6540-6550. Medline

Nguyen MQ, Zhou Z, Marks CA, Ryba NJ, Belluscio L (2007) Prominent roles for odorant receptor coding sequences in allelic exclusion. Cell 131: 1009-1017. CrossRef Medline

Oka Y, Katada S, Omura M, Suwa M, Yoshihara Y, Touhara K (2006) Odorant receptor map in the mouse olfactory bulb: in vivo sensitivity and specificity of receptor-defined glomeruli. Neuron 52:857-869. CrossRef Medline

Reed RR (1992) Signaling pathways in odorant detection. Neuron 8:205209. CrossRef Medline

Rothman A, Feinstein P, Hirota J, Mombaerts P (2005) The promoter of the mouse odorant receptor gene M71. Mol Cell Neurosci 28:535-546. CrossRef Medline

Saito H, Kubota M, Roberts RW, Chi Q, Matsunami H (2004) RTP family members induce functional expression of mammalian odorant receptors. Cell 119:679-691. CrossRef Medline

Schild D, Restrepo D (1998) Transduction mechanisms in vertebrate olfactory receptor cells. Physiol Rev 78:429-466. Medline

Schwob JE (2002) Neural regeneration and the peripheral olfactory system. Anat Rec 269:33-49. CrossRef Medline

Singla V, Reiter JF (2006) The primary cilium as the cell's antenna: signaling at a sensory organelle. Science 313:629-633. CrossRef Medline

Strotmann J, Levai O, Fleischer J, Schwarzenbacher K, Breer H (2004) Olfactory receptor proteins in axonal processes of chemosensory neurons. J Neurosci 24:7754-7761. CrossRef Medline

Tegoni M, Pelosi P, Vincent F, Spinelli S, Campanacci V, Grolli S, Ramoni R, Cambillau C (2000) Mammalian odorant binding proteins. Biochim Biophys Acta 1482:229-240. CrossRef Medline

Touhara K, Vosshall LB (2009) Sensing odorants and pheromones with chemosensory receptors. Annu Rev Physiol 71:307-332. CrossRef Medline

Varnet-Maury E, Polak EH, Demael A (1984) Structure-activity relationship of stress-inducing odorants in the rat. J Chem Ecol 10:1007-1018. CrossRef

Walters E, Grillo M, Oestreicher AB, Margolis FL (1996) LacZ and OMP are co-expressed during ontogeny and regeneration in olfactory receptor neurons of OMP promoter-lacZ transgenic mice. Int J Dev Neurosci 14: 813-822. CrossRef Medline

Wang MM, Reed RR (1993) Molecular cloning of the olfactory neuronal transcription factor Olf-1 by genetic selection in yeast. Nature 364:121126. CrossRef Medline

Wang MM, Tsai RY, Schrader KA, Reed RR (1993) Genes encoding components of the olfactory signal transduction cascade contain a DNA binding site that may direct neuronal expression. Mol Cell Biol 13:5805-5813. Medline

Washburn KB, Turner TJ, Talamo BR (2002) Comparison of mechanical agitation and calcium shock methods for preparation of membrane frac- 
tion enriched in olfactory cilia. Chem Senses 27:635-642. CrossRef Medline

Wilson C, Venditti R, Rega LR, Colanzi A, D’Angelo G, De Matteis MA (2011) The Golgi apparatus: an organelle with multiple complex functions. Biochem J 433:1-9. CrossRef Medline

Yoshihara Y, Kawasaki M, Tamada A, Fujita H, Hayashi H, Kagamiyama H, Mori K (1997) OCAM: a new member of the neural cell adhesion mol- ecule family related to zone-to-zone projection of olfactory and vomeronasal axons. J Neurosci 17:5830-5842. Medline

Yoshihara Y, Mizuno T, Nakahira M, Kawasaki M, Watanabe Y, Kagamiyama H, Jishage K, Ueda O, Suzuki H, Tabuchi K, Sawamoto K, Okano H, Noda T, Mori K (1999) A genetic approach to visualization of multisynaptic neural pathways using plant lectin transgene. Neuron 22:33-41. CrossRef Medline 